\title{
Study by vaginal cytology of ovarian function in pre-menopausal women
}

\author{
Pravin V. Mehta \\ M.D., D.G.O., M.I.A.C. \\ Mother and Child Hospital, Gita, Pandita Ramabai Road, Gamdevi, Bombay-400 007 - India
}

\begin{abstract}
Summary
In the pre-menopausal years, the ovarian secretion waxes and wanes until its cessation. In this study of women in the pre-menopausal period neither did the menstrual pattern prove to be a reliable criterion by which to judge the extent of oestrogen effect or deficiency nor was there correlation between serial colpocytology and endometrial histology, Hyperplasia of the endometrium was seen with different degrees of oestrogen status and in the menopause. Maximum cases of hyperplasia were seen in the irregularly menstruating group of women. It is therefore emphasized that before beginning oestrogen therapy, both colpocytology and endometrial histology should concur to establish oestrogen deficiency. A close watch should be kept on cases showing an endometrial hyperplasia.
\end{abstract}

\section{Introduction}

Oestrogen replacement therapy to correct oestrogen insufficiency occurring at the menopause is advocated to prevent undesirable metabolic changes such as osteoporosis, atherosclerosis, and atrophic changes of skin and connective tissue. This replacement therapy has been the subject of much controversy on account of the fear of endometrial cancer being caused by exogenous oestrogen (see 'Discussion').

The object of the present study was to detect the beginning of oestrogen deficiency. This requires a prospective follow-up from the age of 35 years, from which time the menopause may start, sometimes abruptly. Serial vaginal cytology and periodic endometrial histology were used to observe the transition from regular menstruation to the menopause. During this transition the irregular menstrual cycles may indicate a variety of endometrial pathology owing to the erratic oestrogen production by the failing ovaries. Thus, the women predisposed to hyperstimulation of the endometrium can be sorted out for close observation during any subsequent oestrogen replacement therapy.

Paper presented at the VIth International Congress of Cytology, Tokyo, Japan, May 2-5, 1977.

\section{Materials and methods}

From January 1973 to January 1977, 300 women 35 years and above were seen in the perimenopausal clinic at the Mother and Child Hospital, Bombay, India. They were asked to report at least every three months when their symptoms and detailed menstrual history were recorded. Serial colpocytology and endometrial histology were done every year. One hundred and eighty women were followed-up for 2 to 3 years.

All were aged not less than 35 and not more than 49 years; and were multiparous and free from any systemic disease, pelvic pathology and vaginal infection. At the time of their first visit, ninety-one were regularly menstruating, fifty-six had irregulap cycles of two months' to one year's interval, an thirty-three were in their menopause. They wer sorted into age groups of 5-year intervals.

The oestrogenic status was evaluated by serial smears taken from the upper one-third of the lateral vaginal wall, after administration of a chloramphenicol pessary for two consecutive days, and were stained by a modified Papanicolaou method (Pastakia, 1955). In the normally menstruating were smears women ,taken from day eight to day twenty-four, when endometrial biopsy was done. The karyopyknotic index(KI) was tabulated according to the age group ofthe patient and day of the cycle.

In the irregularly menstruating group and the menopausal women, smears were taken on alternate days over a period of $\mathbf{3 0}$ to $\mathbf{4 0}$ days to ensure that any oestrogen peak that occurred was noted. An endometrial biopsy was done after the last smear collection.

The oestrogen status was classified as follows:
A. Good, KI $>30$
B. Moderate, KI 11-30
C. Slight, KI 1-10
D. Slight deficiency, intermediate cells only
E. Moderate deficiency, intermediate + few para- basal cells
F. Severe deficiency, parabasal cells only

The histology slides were read by a pathologist who was unaware of the clinical data of the patients. 


\section{Results}

In the regularly menstruating women of all the three age groups (35-39 years; 40-44 years; 45-49 years), the mean KI curve shows a distinct midcycle peak (Fig. 1a, b, and c). The wide variation of the KI values on the same day of the cycle in these
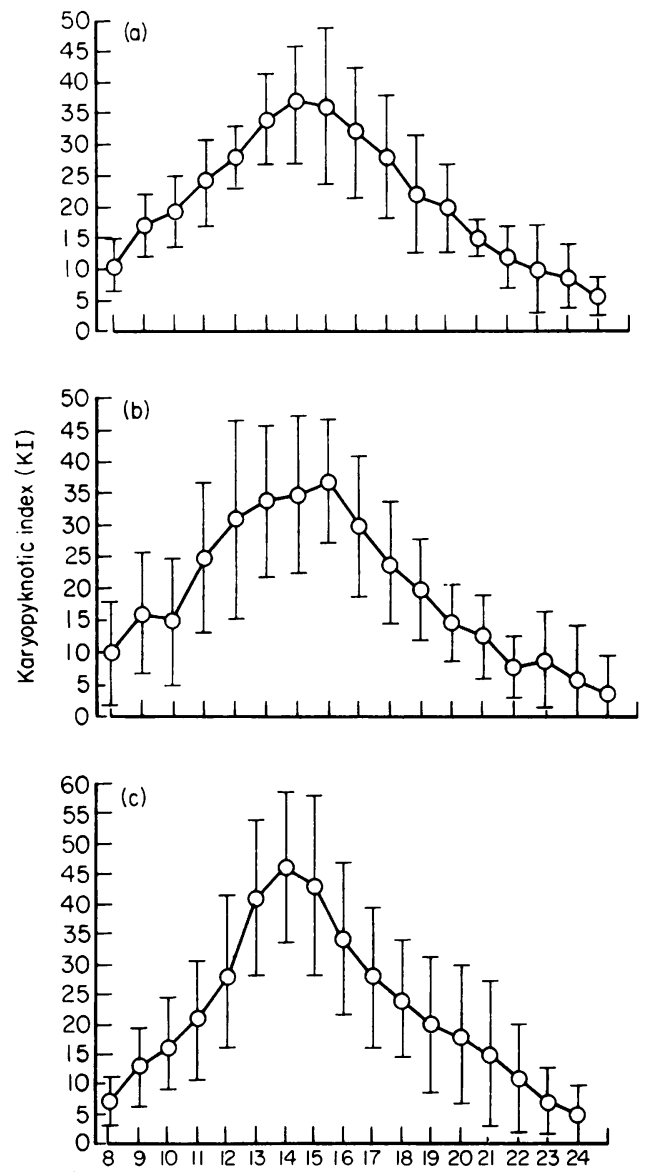

FIG. 1. The mean karyopyknotic index (KI) curve for the regularly menstruating women of all three age groups in the study: (a) 35-39 years, (b) 40-44 years, (c) $45-49$ years. age groups is very evident when the highest, mean, and lowest $\mathrm{KI}$ values (Table 1) are evaluated from day eleven to day fifteen. This shows that random determination of the $\mathrm{KI}$ is meaningless, and emphasizes the importance of multiple serial smears for the correct evaluation of the hormonal status.

The oestrogen status of the regularly and irregularly menstruating and the menopausal women in the three age groups is shown in Table 2. Seven women were menstruating regularly and yet they showed only slight oestrogen effect. In the irregularly menstruating group twenty-four showed good oestrogen effect, and two had severe oestrogen deficiency. In the menopausal group, nine had good oestrogen effect although all nine were $>40$ years old, and one who was $<40$ years old had severe oestrogen deficiency.

The correlation of oestrogen status with endometrial histology, with mean $\mathrm{KI}$ at its peak is seen in Table 3.

Three menopausal women had secretory endometrium although the colpocytology indicated oestrogen deficiency. On the other hand, five menopausal women showed good oestrogen effect, while the endometrium was atrophic. Moreover, in two menopausal women with good oestrogen effect, there was silent hyperplasia. Hyperplasia was also detected in five regularly menstruating and two irregularly menstruating women showing good oestrogen effect. Again, in the irregularly menstruating women, three with moderate oestrogen effect and three with slight effect showed hyperplasia.

Another striking observation was the presence of fairly good oestrogenic effect in sixteen of twentyeight cases with atrophic endometrium.

\section{Discussion}

Substitution therapy has been recommended for the peri-menopausal years, when the circulating oestrogens are inadequate, by some authors (Greenblatt, Colle and Mahesh, 1976; Kistner, 1973; Nordin et al., 1975; Utian, 1975) and opposed by others (Food and Drug Administration, 1976; Herrmann,. 1968; Smith et al., 1975; Ziel and Finkle, 1975).

TABLE 1. Daily variation of the karyopyknotic index (KI) in different age groups

\begin{tabular}{|c|c|c|c|c|c|c|c|c|c|c|c|c|c|c|c|}
\hline \multirow{2}{*}{$\begin{array}{l}\text { Age group } \\
\text { (years) }\end{array}$} & \multicolumn{15}{|c|}{ Day of cycle } \\
\hline & $\mathbf{H}$ & $\begin{array}{l}11 \\
\mathbf{M}\end{array}$ & $\mathbf{L}$ & $\mathbf{H}$ & $\begin{array}{l}12 \\
M\end{array}$ & $\mathbf{L}$ & $\mathbf{H}$ & $\begin{array}{l}13 \\
\mathbf{M}\end{array}$ & $\mathbf{L}$ & $\mathbf{H}$ & $\begin{array}{l}14 \\
M\end{array}$ & $\mathbf{L}$ & $\mathbf{H}$ & $\begin{array}{l}15 \\
M\end{array}$ & $\mathbf{L}$ \\
\hline $35-39$ & 38 & 24 & 16 & 39 & 28 & 20 & 48 & 35 & 21 & 48 & 37 & 21 & 61 & 36 & 19 \\
\hline $40-44$ & 55 & 25 & 11 & 69 & 31 & 17 & 62 & 34 & 20 & 65 & 35 & 15 & 71 & 37 & 10 \\
\hline $45-49$ & 36 & 21 & 12 & 53 & 28 & 12 & 71 & 42 & 19 & 72 & 47 & 25 & 83 & 44 & 15 \\
\hline
\end{tabular}

$\mathbf{H}=$ high, $\mathbf{M}=$ mean, $\mathbf{L}=$ low. 
TABLE 2. The distribution of patients according to their oestrogen status and menstrual pattern in three age groups

\begin{tabular}{|c|c|c|c|c|c|c|c|c|c|}
\hline \multirow{2}{*}{$\begin{array}{l}\text { Menstrual pattern } \\
\text { and age group }\end{array}$} & \multicolumn{2}{|c|}{35 to 39 years } & \multirow[b]{2}{*}{$\begin{array}{l}\text { Meno- } \\
\text { pause }\end{array}$} & \multicolumn{2}{|c|}{40 to 44 years } & \multirow[b]{2}{*}{$\begin{array}{c}\text { Meno- } \\
\text { pause }\end{array}$} & \multicolumn{2}{|c|}{45 to 49 years } & \multirow[b]{2}{*}{$\begin{array}{l}\text { Meno- } \\
\text { pause }\end{array}$} \\
\hline & Regular & Irregular & & Regular & Irregular & & Regular & Irregular & \\
\hline $\begin{array}{l}\text { Good } \\
\text { effect }\end{array}$ & $\begin{array}{c}27 \\
81 \cdot 8 \%\end{array}$ & $\begin{array}{c}4 \\
50 \cdot 0 \%\end{array}$ & - & $\begin{array}{c}27 \\
71 \cdot 1 \%\end{array}$ & $\begin{array}{c}15 \\
48 \cdot 4 \%\end{array}$ & $\begin{array}{c}3 \\
27 \cdot 3 \%\end{array}$ & $\begin{array}{c}15 \\
75 \cdot 0 \%\end{array}$ & $\begin{array}{c}5 \\
29 \cdot 4 \%\end{array}$ & $\begin{array}{c}6 \\
30.0 \%\end{array}$ \\
\hline $\begin{array}{l}\text { Moderate } \\
\text { effect }\end{array}$ & $\begin{array}{c}5 \\
15 \cdot 2 \%\end{array}$ & $\begin{array}{c}3 \\
37 \cdot 5 \%\end{array}$ & 一 & $21 \cdot 8 \%$ & $\begin{array}{c}4 \\
12 \cdot 9 \%\end{array}$ & $9 \cdot 1 \%$ & $10 \cdot 0 \%$ & $\begin{array}{l}3 \\
17 \cdot 7 \%\end{array}$ & $\begin{array}{c}5 \\
25 \cdot 0 \%\end{array}$ \\
\hline $\begin{array}{l}\text { Slight } \\
\text { effect }\end{array}$ & $3 \cdot 0 \%$ & $12 \cdot 5 \%$ & - & $\begin{array}{c}3 \\
7 \cdot 9 \%\end{array}$ & $\begin{array}{c}9 \\
29 \cdot 0 \%\end{array}$ & $9 \cdot 1 \%$ & $\begin{array}{l}3 \\
15 \cdot 0 \%\end{array}$ & $\begin{array}{c}7 \\
41 \cdot 1 \%\end{array}$ & $\begin{array}{c}2 \\
10.0 \%\end{array}$ \\
\hline $\begin{array}{l}\text { Slight } \\
\text { deficiency }\end{array}$ & 一 & - & - & - & $\begin{array}{c}3 \\
9 \cdot 7 \%\end{array}$ & $\begin{array}{c}3 \\
27 \cdot 3 \%\end{array}$ & 一 & - & $\begin{array}{c}2 \\
10.0 \%\end{array}$ \\
\hline $\begin{array}{l}\text { Moderate } \\
\text { deficiency }\end{array}$ & 一 & - & $50 \%$ & - & - & $27 \cdot 3 \%$ & - & - & $\begin{array}{c}5 \\
25 \cdot 0^{\circ}\end{array}$ \\
\hline $\begin{array}{l}\text { Severe } \\
\text { deficiency }\end{array}$ & 一 & - & $50 \%$ & - & 一 & - & - & $\begin{array}{c}2 \\
11 \cdot 8 \%\end{array}$ & - \\
\hline Total $(100 \%)$ & 33 & 8 & 2 & 38 & 31 & 11 & 20 & 17 & 20 \\
\hline
\end{tabular}

\section{Age and oestrogen status}

In an attempt to establish the criteria that could be used for the selection of menopausal patients for oestrogen therapy, Meisels (1966) found that not all menopausal women showed oestrogen deficiency, as $40 \%$ of his patients demonstrated some oestrogen effect and as many as $10 \%$ of them had high oestrogenic values. Even in the present study, out of the 33 menopausal cases, $15(45.4 \%)$ showed good or moderate oestrogen effect $(\mathrm{KI}>10)$ and $3(9 \cdot 1 \%)$ slight (KI 0-10\%) (Table 3). This shows that women, although in their menopause, have varying degrees of circulating oestrogen. Stoll (1960) as well as Masukawa (1960) observed that many women show a hormonally stimulated vaginal epithelium up to an advanced age. Thus, decrease in circulating oestrogen in peri-menopausal women cannot be related linearly with increased age.

Since the controversy of oestrogen replacement therapy surrounds its effects on the endometrium, a study of the endometrial histology in the menopausal women and the peri-menopausal group is of paramount importance.

The histology of the endometrium when correlated with oestrogen status and menstrual pattern in the present study (Table 3) showed very interesting features.

\section{Histology and menstrual pattern}

Of the women with a good oestrogen effect, two menopausal, five menstruating regularly, and eight irregularly (but with varying degrees of oestrogen) showed hyperplasia. Oestrogen-replacement therapy in these women, especially those in the menopause and those with irregular cycles, could have proved harmful. Kistner (1976) rightly points out that the therapeutic misuse of oestrogenic substances can produce varying degrees of endometrial hyperplasia. In certain predisposed women the latter may lead to carcinoma if such stimulation is continued. Prospective studies by Gusberg and Kaplan (1963) showed that $12-14 \%$ of a typical adenomatous hyperplasia (called carcinoma in situ) and cystic hyperplasia will progress to invasive cancer under the continued administration of oestrogen. Hence it can be emphasized that the menstrual history is not a safe criterion for the initiation of oestrogen therapy but that a serial colpocytology must be done to ascertain the amount of oestrogen already circulating in the body to avoid any hyperstimulation of the endometrium.

\section{Histology and colpocytology}

In eight menopausal women, one menstruating regularly and one irregularly, the colpocytology revealed moderate to good oestrogen effect, but the endometrium was refractory and showed atrophy. In three menopausal women, showing varying degrees of oestrogen deficiency but secretory endometrium, freak ovulation may have occurred. In the cases of hyperplasia, in the menopausal as well as the irregularly menstruating group, the endometrium reflected the cumulative effect of persisting oestrogen. In the latter group, the mean KI at peak was only $28 \cdot 14$.

Thus, colpocytology, alone, can be misleading and this stresses the fact that both serial cytology and endometrial histology are essential, especially when oestrogen therapy is contemplated. 


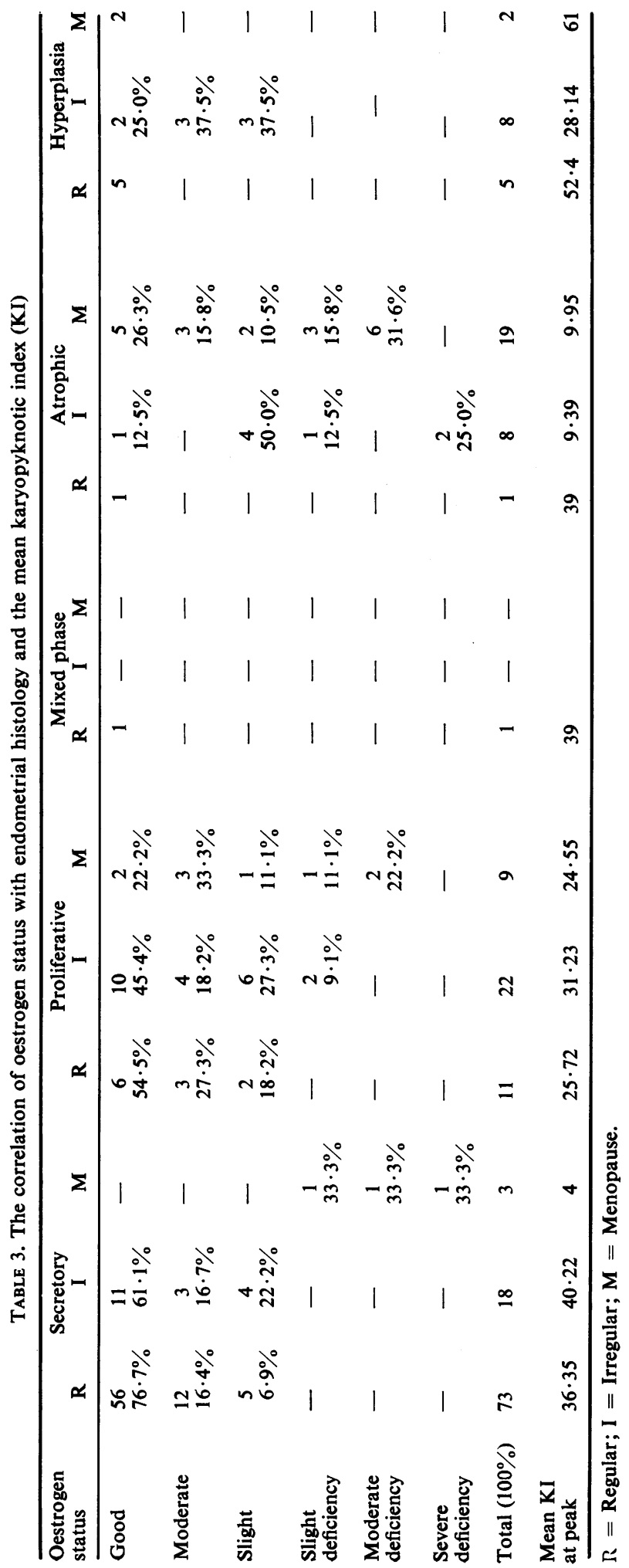




\section{Conclusion}

In order to select cases for oestrogen-replacement therapy, colpocytology and endometrial histology should be carried out together to ascertain oestrogen deficiency; this is particularly important in cases showing endometrial hyperplasia.

\section{Acknowledgment}

I thank $\operatorname{Dr} A$. R. Chitale for the reading of the histopathology slides.

\section{References}

Food AND Drug Administration (1976) Estrogens and endometrial cancer. Drug Bulletin, 6, 18.

Greenblatt, R.B., Colle, M.L. \& Mahesh, V.B. (1976) Ovarian and adrenal steroid production in the postmenopausal woman. Obstetrics and Gynecology, 47, 383.

Gusberg, S.B. \& Kaplan, A.L. (1963) Precursors of corpus cancer: IV. Adenomatous hyperplasia as stage $\mathbf{O}$ carcinoma of the endometrium. American Journal of Obstetrics and Gynecology, 87, 662.

HerrmanN, W.L. (1968) Estrogen administration in menopause - An invitational symposium. Lying in: The Journal of Reporoductive Medicine, 1, 237.
KISTNER, R.W. (1973) The menopause. Clinical Journal of Obstetrics and Gynecology, 16, 106.

KISTNER, R.W. (1976) Estrogen and endometrial cancer. $\stackrel{\mathbb{Q}}{\varrho}$ Obstetrics and Gynecology, 48, 479.

MasukaWA, T. (1960) Vaginal smear in women past forty years of age, with emphasis on their remaining hormonal $\stackrel{5}{\vec{D}}$ activity. Obstetrics and Gynecology, 16, 407.

MeISELS, A. (1966) The menopause: a cytohormonal study. Acta cytologica, 10, 49.

Nordin, B.E.C., Gallagher, J.C., Aaron, J.E. \& Horsman, $\frac{\bar{\omega}}{\partial}$

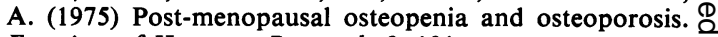
Frontiers of Hormone Research, 3, 131.

PASTAKIA, H.J. (1955) The vaginal smear. Indian Journal of Medical Science, 9, 579.

Smith, D.C., Prentice, R., Thompson, D.J. \& Herrmann, W.L. (1975) Association of exogenous estrogen and endo- $\overrightarrow{\vec{\omega}}$ metrial carcinoma. New England Journal of Medicine, 293, 1164.

Stoll, P. (1960) Vaginal smears in the menopause, Symposium on Effect of Endogenous Oestrogens on the Vaginal Epithelium. Acta cytologica, 2, 148.

UtIAN, A.H. (1975) Osteoporosis, oestrogens and oöpherectomy-A proposed new test of oestrogenic potency. W South African Medical Journal, 49, 433.

ZIEL, H.K. \& FINKLE, W.D. (1975) Increased risk of endometrial carcinoma among users of conjugated estrogens. $\sigma$ New England Journal of Medicine, 293, 1167. 


\section{CORRIGENDA}

Postgraduate Medical Journal June 1978 Vol. 54 No. 632

Page 386, paragraph 3 of right column.

Lines 6 and 7:

for ... In the normally menstruating were smears women, taken ...

read ... In the normally menstruating women, smears were taken ...

Page 401, paragraph 2 of right column.

Line 5:

for . . . of 20 years of less comprised $26 \%$ of the series.

read . . . of 20 years or less comprised $26 \%$ of the series. 